\title{
Thermal Comfort in an Office Room Using Square Diffuser
}

\author{
Alper Yildirim ${ }^{1 *}$ (i), Coskun Ozalp² \\ 'Osmaniye Korkut Ata University, Department of Machinery and Metal Technology, Osmaniye, Turkey \\ ${ }^{2}$ Osmaniye Korkut Ata University, Engineering Faculty, Energy System Eng. Dept., Osmaniye, Turkey
}

\begin{abstract}
The office is an important part of daily life, people spend most of their time working inside of the office and thus the quality of the indoor air environment is a significant factor affecting the productivity and happiness of office users. Many factors influence the pattern of airflow: indoor air quality, thermal comfort and energy saving in an office room. In this study, the effects of the square diffusers on thermal comfort investigated numerically for an office room. Numerical research was subsequently carried out using the validated CFD (computational fluid dynamics) model. This model solved the continuity, energy conservation and momentum equations in addition to $k-\varepsilon$ model equation for turbulence modelling. Predicted Percentage of Dissatisfied (PPD) is a frequently used tool for assessing human comfort rating. A PPD based control HVAC (Heating, Ventilating and Air Conditioning) system has the potential to provide enhanced thermal comfort inside a location by taking into consideration all main thermal comfort variables. The CFD results revealed that the PPD values in the room varies on average between $10 \%$ and $20 \%$ and thus thermal conditions occurred according to ASHRAE standards in the model office room with a square diffuser.
\end{abstract}

Keywords: CFD, Diffuser, HVAC, PMV, PPD, Thermal Comfort

\section{INTORDUCTION}

The Heating, Ventilating and Air Conditioning (HVAC) system's most critical goal is to develop a comfortable and healthy environment and reduce indoor pollutant concentration. An effective design of HVAC system involves the appropriate installation of the exhaust and supply outlet with regard to a room's geometry configuration, distribution of indoor thermal conditions and indoor heat sources. The ventilation efficiency and energy saving in most air distribution systems are greatly affected by the supply, return and exhaust diffuser location arrangements [1]. If the ventilation process is incomplete or incorrect in the occupied zone, there is a possibility that people in these places may lose their working efficiency and even deteriorate their health. The first condition to be considered in order to prevent this unwanted possibility is the cleanliness of the air. Air temperature, air distribution and velocity in the area are other important elements. Thermal comfort is the definition of the comfort of the people in the occupied zone while continuing their physical or mental activities under physical factors such as temperature, humidity and air circulation. Thermal comfort is felt after a certain period of time in the occupied zone [2]. The main factors affecting thermal comfort conditions are given below [3].

\subsection{Personal Factors}

Clothing: The resistance given by clothing to reasonable heat gain transfer.

Metabolic heat: It is the heat person produce by physical activity. The stationary person will tends to feel colder than the exercise person. [4].

\subsection{Environmental Factors}

Air velocity: The velocity of the air that the person touches. The faster the air moves, the higher the heat exchange between the air and the person.

Air Temperature: The temperature of the air around the body (dry-bulb).

Radiant Temperature: Expressed as the temperature of an environment (including heat generating equipment, surfaces, sky and sun). This is commonly defined as the mean radiant temperature (MRT) and any strong unidirectional radiation such as radiation from the sun.

Air humidity: It is defined as the ratio of water vapor to a given volume of air.

Awad et al. [5] used various exhaust diffuser locations to investigate velocity distribution and air flow patterns. The 
results revealed that the location of the exhaust diffuser had a significant impact on the level of the layers of thermal stratification that influenced the cooling coil load as a result. Cheng et al.[6] reported that $20.8 \%$ of energy savings were achieved when the supply inlet was located at the floor level and the return outlet was located at the occupied level. They also found that the distribution of the supply diffuser improved energy saving and indoor thermal comfort in the occupied zone. Chung and Kuo [7] used the effect of the supply and outlet diffusers places on indoor thermal comfort using various ventilation strategies in the occupied zone. Based on simulation result, they discovered that the longer supply air throw in the occupied region is, a much better the indoor thermal comfort obtained. He et al. [8] noted that the position of the exhaust vent did not considerably influence the pattern of air flow, but could considerable affect the level of indoor exposure.

The sensitivity of the PMV (Predicted Mean Vote) index was analyzed by d'Ambrosio Alfano et al. [9] for the accuracy of its six independent variables, including air temperature, mean radiant temperature, air velocity, metabolic rate, insulation of the clothing and relative humidity. The authors found that due to a substantial Sensitivity of PMV that mostly reaches or exceeds the A class width $( \pm 0.20)$, the PMV comfort ranges published in the EN 15251 and ISO 7730 standards should be extended to permit for a more sustainable category of thermal indoor environment. In order to optimize the thermal environment in a train station with a high ceiling. Li et al. [10] evaulated various air distribution models. The numerical result showed that satisfactory thermal comfort was achieved using air distribution design and a stratified supplying air at midheight horizontally in the occupied region. Similarly, Han and Gu [11] conducted a numerical study of the thermal environment at Beijing International Airport. They reported that a satisfactory thermal environment was achieved in the occupied zone through the use of stratified air distribution in the terminal building. Three ventilation techniques (i.e. natural ventilation [NV], air conditioning $[\mathrm{AC}]$, and hybrid $[\mathrm{HB}]$ ) were used by Lau et al. [12] to evaulate the thermal comfort of the occupants of educational facilities on a tropical university campus. Results showed that HB spaces have a significant advantage in terms of a higher rates of neutral thermal sensation votes, an overall level of thermal comfort, and temperature satisfaction levels over NV and AC spaces. It was also discovered, as compared to those in the AC spaces, occupants in $\mathrm{NV}$ and $\mathrm{HB}$ spaces maintained higher comfort temperatures and they may tolerate a larger range of acceptable temperatures. The goal of Khalil et al. [13]. is to evaluate and analyze the indoor thermal comfort in different cases in order to assign the correct inlet air temperature to the operating room. For this study, the PMV and PPD (Predicted Percentage of Dissatisfied) models in accordance with ISO 7730 were used. The results showed that inlet air temperature has a slight effect on the airflow patterns and air velocities inside the operating room at the same air change rate.
The PMV is one of the most well-known thermal comfort models. The standards firstly implemented by Fanger, ASHRAE 55 and ISO 7730 are based on that model. The PMV is an index that forecasts the mean value of the votes of a large number of people on a 7-point thermal sensation scale. It is based on the heat balance of the human body. When internal heat production is equal to the loss of heat to the environment in the body, thermal balance is achieved. Thermal sensitivity scale measurement ranges for thermal comfort are shown in Table 1 and numerical values of PMV and PPD (Predicted Percentage Dissatisfied) are seen in Figure 1. PPD indicates the estimated number of person who are not satisfied with their comfort condition[3]. As seen in figure 1, the suggested thermal limit for the 7-point PMV scale is between- 0.5 and 0.5 in order to meet ASHRAE 55 requirements. Depending on the calculated PMV, the PPD may range from 5 percent to 100 percent. In order for the comfort ranges to comply with the standards, no space occupied point should be more than 20\% PPD.

In this study, thermal comfort conditions were investigated by using a square diffuser in the office room.

Table 1. PMV index [14]
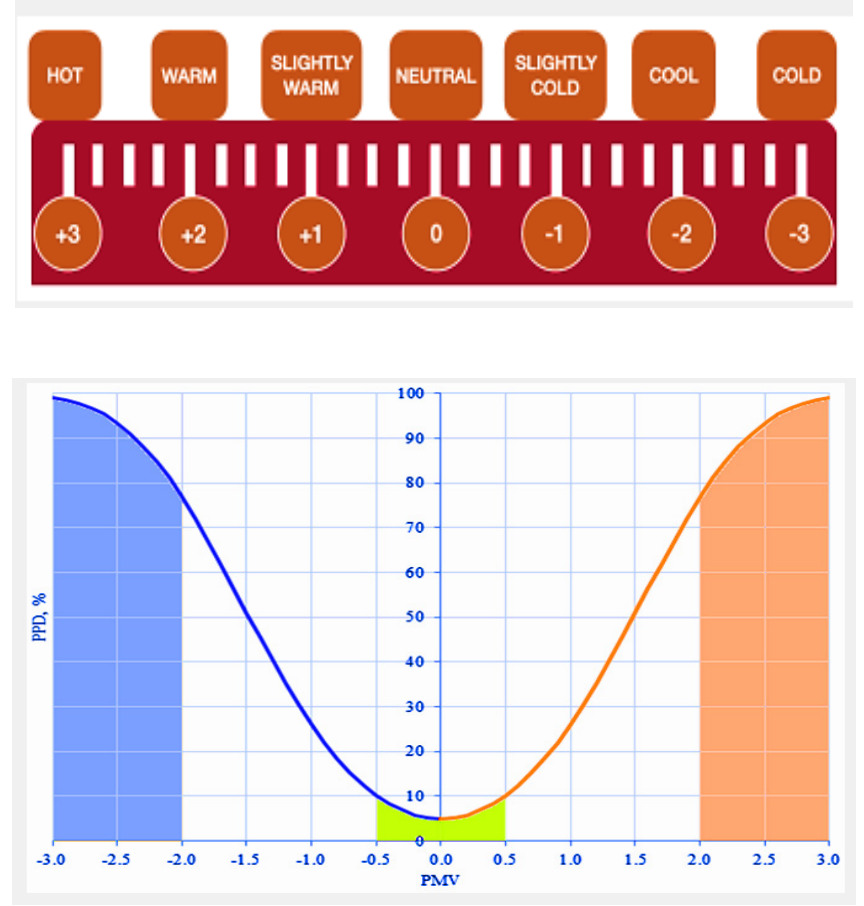

Figure 1. PPD numerical as a function of PMV values [15] to create a suitable thermal condition in avoiding occupant dissatisfaction, adverse effect on their roductivity and overall building performance. Approach: Assessment was conducted using Babuc-A (Portable air quality monitor

\section{2. MATERIAL AND METHODS}

\subsection{1 Mahtematical Models}

In present study, commercial package "FLUENT 18" is used to solve and transform the partial differential equations based on the "SIMPLE" algorithm. More dense mesh structure was created in regions where velocity and temperature changes are high. For this reason, the exit part of the mesh and the surfaces around the geometries in the office model 
are the parts with the most dense mesh structure and in other regions, less frequent mesh structure is preferred.

The indoor air was steady-state, incompressible flow and coincidence with the basic assumption of Boussinesq, invariable property. Considering the influence of buoyant force in the turbulence model, equation. Realizable k- $\varepsilon$ model with the wall-function method were used.. Conservation of mass, energy and momentum equations as follows [16]:

$$
\begin{aligned}
& \frac{\partial u}{\partial x}+\frac{\partial v}{\partial y}=0 \\
& \frac{\partial}{\partial x}(\rho u u)+\frac{\partial}{\partial y}(\rho u v)=-\frac{\partial p}{\partial x}+2 \frac{\partial}{\partial x}\left(\mu_{e f f} \frac{\partial u}{\partial x}\right)+\frac{\partial}{\partial y}\left[\mu_{e f f}\left(\frac{\partial u}{\partial y}+\frac{\partial v}{\partial x}\right)\right] \\
& \frac{\partial}{\partial x}(\rho u v)+\frac{\partial}{\partial y}(\rho v v)=-\frac{\partial p}{\partial y}+\frac{\partial}{\partial x}\left[\mu_{e f f}\left(\frac{\partial u}{\partial y}+\frac{\partial v}{\partial x}\right)\right]+2 \frac{\partial}{\partial y}\left(\mu_{e f f} \frac{\partial v}{\partial y}\right) \\
& \frac{\partial}{\partial x}(\rho u T)+\frac{\partial}{\partial y}(\rho v T)=\frac{\partial}{\partial x}\left[\left(\frac{\mu}{P r}+\frac{\mu_{t}}{P r_{t}}\right) \frac{\partial T}{\partial x}\right]+\frac{\partial}{\partial y}\left[\left(\frac{\mu}{P r}+\frac{\mu_{t}}{P r_{t}}\right) \frac{\partial T}{\partial y}\right]
\end{aligned}
$$

$\mathrm{k}-\varepsilon$ model turbulence model is chosen which is the two equation Reynolds - Averaged Navier Stokes based model and usually used in heat transfer problems. The Renormalization Group (RNG) k- $\varepsilon$ turbulence model with enhanced wall treatment is selected because of its compatibility with the experimental works. Differential equations for turbulence energy dissipation rate $(\varepsilon)$ and kinetic energy $(k)$ are given in steady state as follows:

$$
\begin{aligned}
& \frac{\partial}{\partial x}(\rho k u)+\frac{\partial}{\partial y}(\rho k v)=\frac{\partial}{\partial x}\left(\alpha_{k} \mathfrak{a}_{e f f} \frac{\partial k}{\partial x}\right)+\frac{\partial}{\partial y}\left(\alpha_{k} \mu_{e f f} \frac{\partial k}{\partial y}\right)+G_{k}-\rho \\
& \frac{\partial}{\partial x}(\rho \varepsilon u)+\frac{\partial}{\partial y}(\rho \varepsilon v)=\frac{\partial}{\partial x}\left(\alpha_{\varepsilon} \mu_{e f f} \frac{\partial \varepsilon}{\partial x}\right)+\frac{\partial}{\partial y}\left(\alpha_{\varepsilon} \mu_{e f f} \frac{\partial \varepsilon}{\partial y}\right)+C_{1 \varepsilon} \frac{\varepsilon}{k} G_{k}-C_{2 \varepsilon} \rho \frac{\varepsilon^{2}}{k}
\end{aligned}
$$

The inverse effective Prandtl numbers of $\varepsilon$ and $\mathrm{k}$ are represented as $\alpha_{k}$ and $\alpha_{\varepsilon}$, respectively. $G_{k}$ denotes the turbulence kinetic energy generation and it is written as:

$$
G_{k}=-\mu_{t}\left[2\left(\frac{\partial u}{\partial x}\right)^{2}+2\left(\frac{\partial v}{\partial y}\right)^{2}+\left(\frac{\partial u}{\partial y}+\frac{\partial v}{\partial x}\right)^{2}\right]
$$

$\mu_{e f f}$ is the effective turbulent viscosity and it can be calculated from;

$$
\mu_{e f f}=\mu+\mu_{t}
$$

$\mu_{t}$ shows the turbulent (or eddy) viscosity,

$$
\mu_{t}=\rho C_{\mu} \frac{k^{2}}{\varepsilon}
$$

where $C_{\mu}=0.0845$. The model constants $c_{1 \varepsilon}$ and $c_{2 \varepsilon}$ are given as 1.42 and 1.68 , respectively

\subsection{Physical Model}

The dimensions of the modeled office room have been chosen as Length $(\mathrm{X}) \times$ Height $(\mathrm{Y}) \mathrm{x}$ Width $(\mathrm{Z})=4 \mathrm{~m} \times 3.5 \mathrm{~m}$ $x 3 \mathrm{~m}$. It has been accepted that there are people, refrigerators, lamps and computers in the room. Heat sources for the modeled office room are given in Table 2. It is acknowledged that the office does not have doors and windows. The configuration of the office room is given in Figure 2.

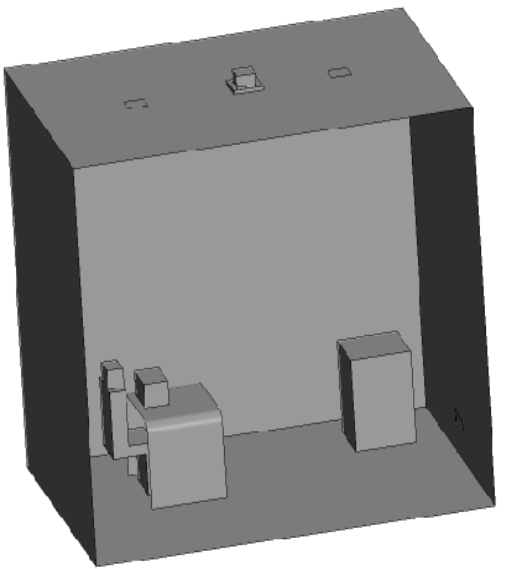

Figure 2. Geometrical arrangement of the office room.

\subsection{Boundary Conditions}

Table 2 shows the boundary condition for velocity and temperature at the air supply and exhaust. The cooling load according to the direction of the building is calculated according to the values given in Table 4. Cooling loads for humans, refrigerators, lamps and computers are taken from

\begin{tabular}{|c|c|c|}
\hline Heat Source & & $\begin{array}{l}\text { Cooling Load } \\
\left(\mathrm{W} / \mathrm{m}^{2}\right)\end{array}$ \\
\hline Person (seated) & & 70 \\
\hline Refrigerator & & 50 \\
\hline Lamp (2 pieces) & & 15 \\
\hline Computer & & 35 \\
\hline West wall & & 4 \\
\hline East wall & & 20 \\
\hline North wall & & 4 \\
\hline South wall & & 21 \\
\hline Floor & & 10 \\
\hline Ceiling & & 10 \\
\hline \multicolumn{3}{|c|}{ Table 4. Heat transfer coefficient values } \\
\hline & $\mathrm{A}\left(\mathrm{m}^{2}\right)$ & $\mathbf{U}\left(\mathrm{W} / \mathrm{m}^{2 \circ} \mathrm{C}\right)$ \\
\hline South & 14 & 1.03 \\
\hline West & 10.5 & 1.03 \\
\hline East & 10.5 & 1.93 \\
\hline North & 14 & 1.93 \\
\hline Ceiling & 12 & 1.2 \\
\hline Floor & 12 & 0.31 \\
\hline
\end{tabular}
the ASHRAE basic manual. Heat sources for the modeled office room are given in Table 3. It is acknowledged that the office does not have doors and windows. Since there are temperature differences in the room, natural convection has occurred in the solution. The effect of Ra number was not examined in the study.

Table 2. Boundary conditions for case study
\begin{tabular}{|c|c|c|c|c|}
\hline Diffuser & Flow Rate $(\mathrm{kg} / \mathrm{s})$ & $\mathrm{T}_{\text {supply }}$ & $\mathrm{T}_{\text {exhaust }}$ & $\mathrm{T}_{\text {outdoor }}$ \\
\hline Square Diffuser(SD) & 0.11 & $13^{\circ} \mathrm{C}$ & $23{ }^{\circ} \mathrm{C}$ & $36{ }^{\circ} \mathrm{C}$ \\
\hline
\end{tabular}

Table 3. Heat sources for the modeled office room.

\subsection{Mesh Independency Study}

For the accuracy of CFD simulations and for the achievement of a fully converged solution, the quality of the grid plays an important role. It should be fine enough, particularly in the close zone of the diffuser, to avoid undesired 
numerical diffusion. The mesh independence is estimated and shown in Figure 3. In order to obtain an independent mesh result, three different mesh were chosen. It has been observed that the results with different mesh numbers are compatible with each other.

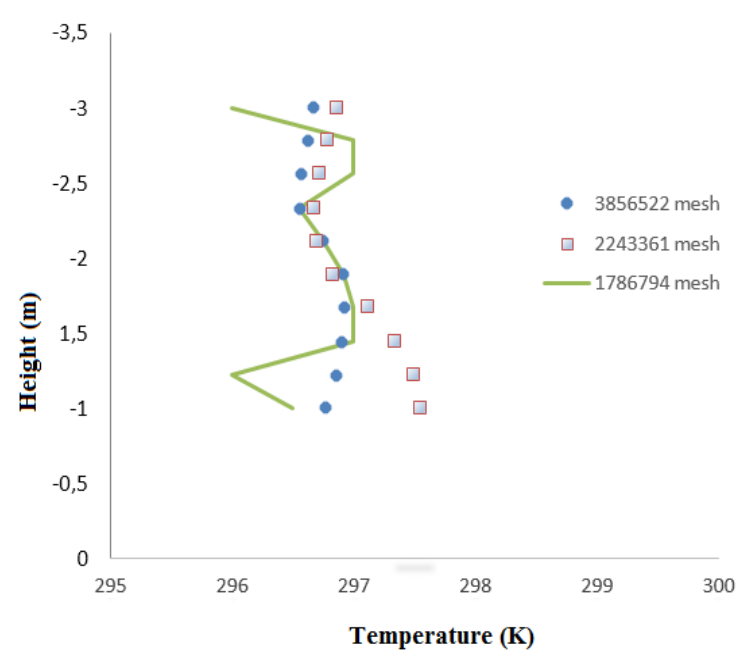

Figure 3. Square diffuser (SD) mesh independence

\subsection{Validation of Study}

Since there are no any studies to compare with described study in the literature, numerical calculations for velocity in the room compared with existing similar studies. The purpose of validation is to demonstrate the ability of the CFD model by using available experimental data to predict velocity. The CFD simulation is validated with experimental results from Particle Image Velocimetry (PIV) [17]. Geometrical and Reynolds number similarity were used to compare numerical study and experimental study. Figure 4 shows the comparisons between simulated and measured air velocity distributions. As a result, measured and simulated data agreed well.

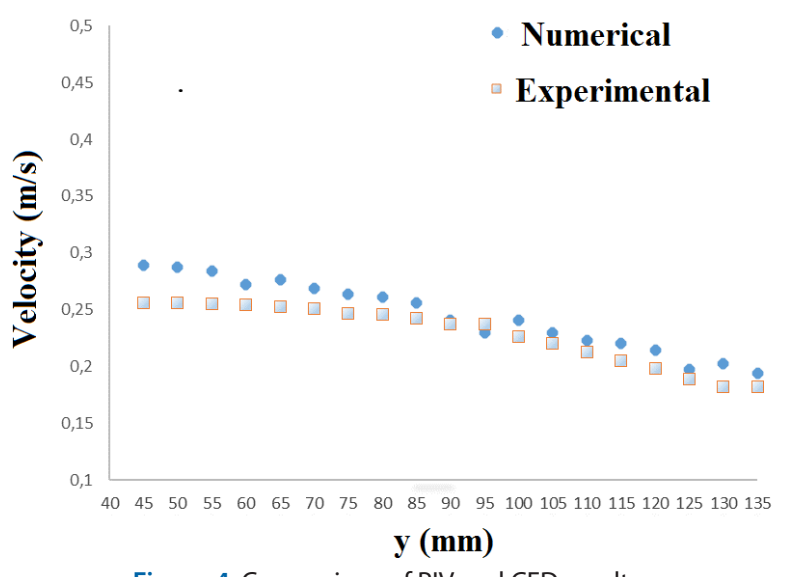

Figure 4. Comparison of PIV and CFD results

\subsection{Calculation of PMV And PPD Values}

While PMV and PPD were calculated, speed and temperature values were obtained from the CFD program. Metabolic rate, $\mathrm{MRT}$, air relative humidity, clothing level values were accepted as $1 \mathrm{~W} / \mathrm{m} 2,2, \% 60$ and $0.6 \mathrm{~m} 2^{\circ} \mathrm{C} / \mathrm{W}$, respectively.
The PMV and equations are expressed as [6];

$$
\begin{aligned}
& P M V=\left[0,303 e^{-0.036 M}+0,028\right] \times\{(M-W) \\
& -3,05 \times 10^{-3} \times\left[5733-6,99(M-W)-p_{a}\right] \\
& -0,42 \times[(M-W)-58,15]-1,7 \times 10^{-5} M\left(5867-p_{a}\right) \\
& -0,0014 M\left(34-t_{a}\right)-3,96 \times 10^{-8} f_{c l} \\
& \left.\times\left[\left(t_{c l}+273\right)^{-4}-(\overline{t r}+273)^{-4}\right]-f_{c l} h_{c}\left(t_{c l}-t_{a}\right) .\right\} \\
& t_{c l}=35,7-0,028(\mathrm{M}-\mathrm{W})-I_{c l}\left\{3,96 \times 10^{-8} f_{c l} \times\left[\left(t_{c l}+273\right)^{-4}-(\overline{t r}+273)^{-4}\right]+f_{c l} h_{c}\left(t_{c l}-t_{a}\right)\right\}(10)
\end{aligned}
$$

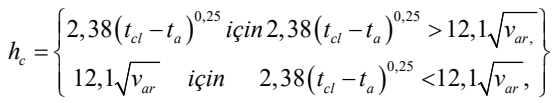

$$
\begin{aligned}
& f_{c l}=\left\{\begin{array}{l}
1.00+1.290 I_{c l} i c ̧ i n I_{c l}<0.078 m^{2}{ }^{\circ} c / w, \\
1.05+0,645 I_{c l} i c ̧ i n I_{c l}>0.078 m^{2}{ }^{\circ} c / w,
\end{array}\right\}
\end{aligned}
$$

PPD is expressed by Fanger as a function of PMV, and its calculation is given in the following equation.

$$
P P D=100-95 e^{-\left(0.03353^{*} P M V^{4}+0,2179 \times P M V^{2}\right)}
$$

\section{RESULTS AND DISCUSSIONS}

The levels of $0.1,0.6$, and 1.1 meters correspond to ASHRAE's recommended measurement heights for seated subjects. Therefore in this study, measuring the airflow temperatures and velocities were set at the height of 0.1, 0.6 and 1.1 meters above the floor [9].

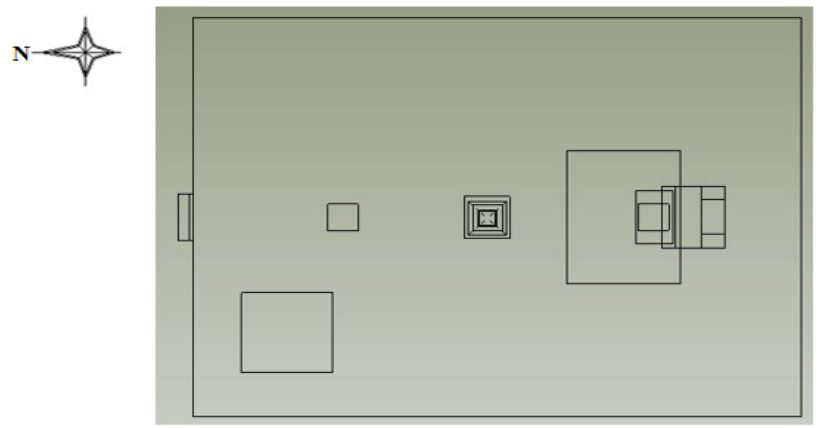

Figure 5. Top view of the office room

The PPD distribution contours of office room at the height of 0. 1, 0.6, and 1.1 are seen in Figure 6, Figure7 and Figure 8 respectively. From the PPD index in Figure 6 and 7, it can be seen that the indoor thermal comfort are uniform. Major portions of the office room are having a PPD value is between 0-20\%. The PPD contours where the value is less than 20 percent indicates that people are likely to feel slightly cool in the north part of the room. The PPD contours are shown for the height of $1.1 \mathrm{~m}$ in Figure 8. The large zone is affected by a PPD $20 \%$ and below. However, the PPD value is varying drastically from 20 to $40 \%$ in the central region of the office room and nearer to north wall face. When the office room, which is generally modeled, is air-conditioned using a square diffuser, it provided the thermal comfort conditions. 


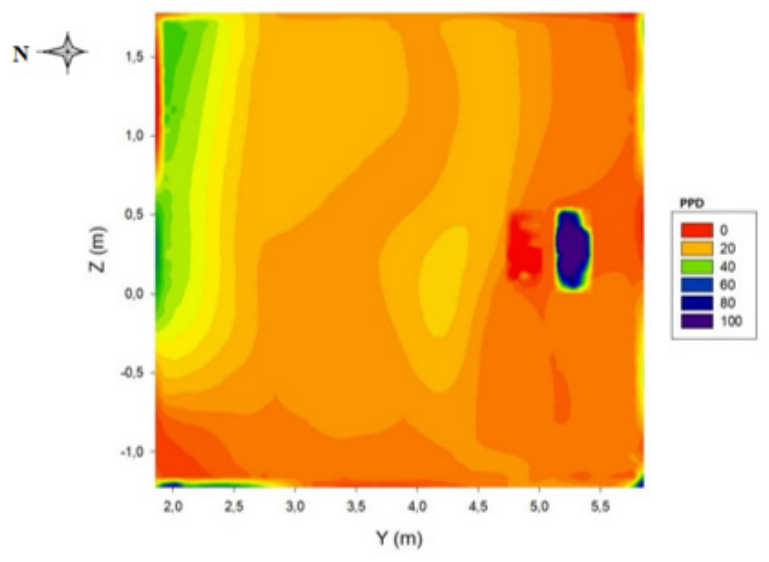

Figure 6. The PPD distribution contour of office room at the height of $0.1 \mathrm{~m}$

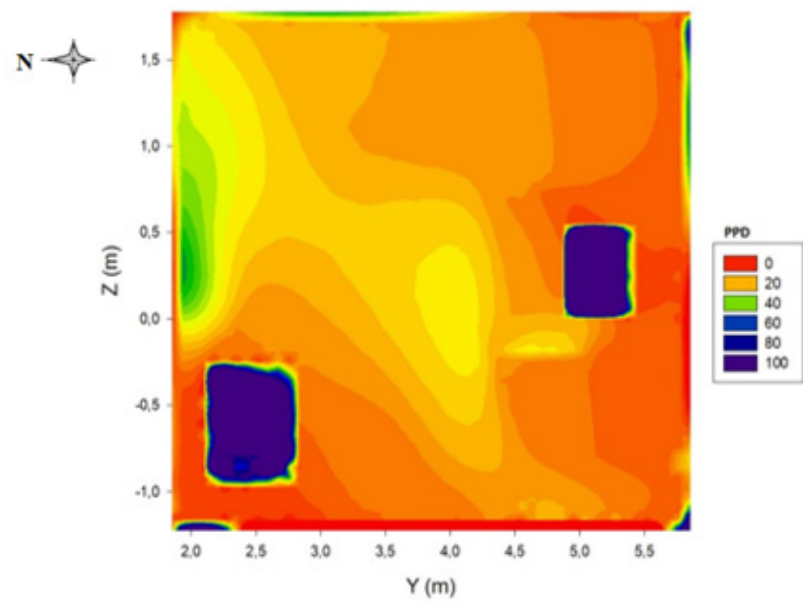

Figure 7. The PPD distribution contour of office room at the height of 0.6

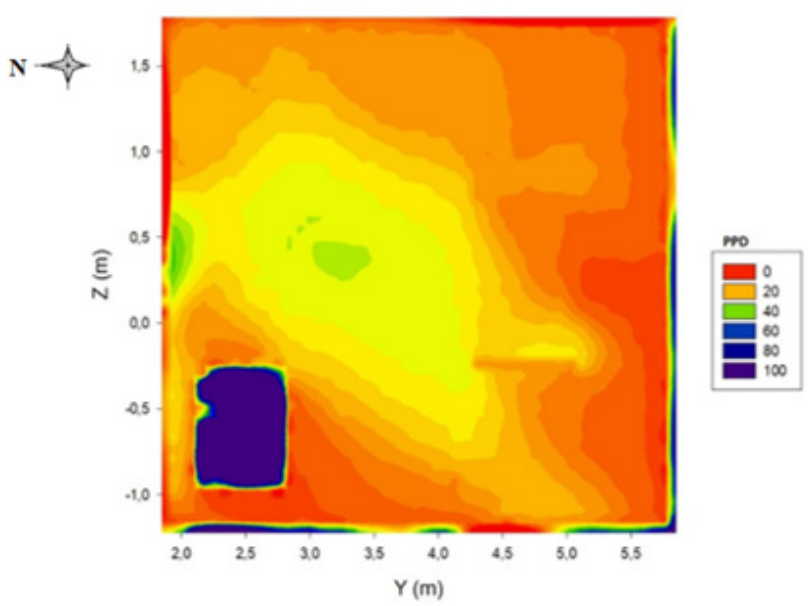

Figure 8. The PPD distribution contour of office room at the height of $1.1 \mathrm{~m}$

\section{CONCLUSION}

In HVAC engineering, CFD, an important tool, has been used to analyze data produced by models representing the complexities of flows evolve in the ventilated spaces. In a simplified office room, this study presents the results of a set of numerical investigations into the performance of square ceiling diffusers. ASHRAE thermal comfort conditions are observed in the air conditioning space with square diffuser. The values of PPD similar at different heights in the model office room. In the place, the PPD is commonly less than $20 \%$. However, the PPD value is varying drastically from 20 percent to 40 percent at the height of 1.1 meter in the some places of room.

The study also show that choosing the diffuser plays an important role in air-conditioning works, providing thermal comfort in home and workplace environments where people are present. In our previous work [18], we changed only the displacement and model of the diffuser in the room with the same physical features as this study. The comparison between two diffusers shows that a square diffuser at the same boundary conditions supplies better thermal comfort conditions of the office room.

As a continuation of this study; Numerical calculations can be made considering that there are objects and people in places with different geometries. While making these numerical calculations, parameters such as diffusers' inlet and outlet locations, diffuser geometry and number, different air velocities, doors and windows can be taken into consideration.

\section{NOMENCLATURE}

$c_{P} \quad$ fluid specific heat, $(\mathrm{kJ} / \mathrm{kg})$

$c_{1 \varepsilon} \quad$ model constant, ref.

$c_{2 \varepsilon} \quad$ model constant, ref.

$f_{c l} \quad$ Ratio of clothed surface area

$h_{c} \quad$ Convection heat transfer coefficient (W/ $\left.\left(\mathrm{m}^{2} . \mathrm{K}\right)\right)$

$P \quad$ Pressure $(\mathrm{Pa})$

$I_{c l} \quad$ Basic clothing insulation $\left(\mathrm{m}^{2} .{ }^{\circ} \mathrm{C} / \mathrm{W}\right)$

M Metabolic rate $\left(\mathrm{W} / \mathrm{m}^{2}\right)$

Pr Prandtl number

$q " \quad$ heat flux $\left(W / m^{2}\right)$

$p_{a} \quad$ Water vapor partial pressure $(\mathrm{Pa})$

Re Reynolds number

$T \quad$ Temperature $\left({ }^{\circ} \mathrm{C}\right)$

$t_{a} \quad$ Ambient air temperature $\left({ }^{\circ} \mathrm{C}\right)$

$t_{r} \quad$ Mean radiant temperature $\left({ }^{\circ} \mathrm{C}\right)$

$t_{c l} \quad$ Clothing surface temperature $\left({ }^{\circ} \mathrm{C}\right)$

W Effective mechanic power $\left(\mathrm{W} / \mathrm{m}^{2}\right)$

$v_{a r} \quad$ Relative air velocity $(\mathrm{m} / \mathrm{s})$

$u \quad$ velocity in $\mathrm{x}$ direction $(\mathrm{m} / \mathrm{s})$

$v \quad$ velocity in y direction $(\mathrm{m} / \mathrm{s})$

$x \quad$ x coordinate

$y \quad$ y coordinate 


\section{Greek}

$\beta \quad$ pressure gradient, eq. (17), $(\mathrm{Pa} / \mathrm{m})$

à energy dissipation rate $\left(m^{2} / s^{3}\right)$

u kinematic viscosity $\left(\mathrm{m}^{2} / \mathrm{s}\right)$

$\theta \quad$ dimensionless temperature, eq.

$\rho \quad$ density $\left(\mathrm{kg} / \mathrm{m}^{3}\right)$

$\Delta p \quad$ pressure loss, eq.

$\mu \quad$ dynamic viscosity $(P a . s)$

$\mu_{t} \quad$ turbulent viscosity, eq.

$\mu_{i \ddot{u}} \quad$ effective turbulent viscosity, eq.

$\alpha_{k} \quad$ inverse effective Prandtl number of k

$\alpha_{\AA} \quad$ inverse effective Prandtl number of å

\section{RERERENCES}

[1] Ahmed, A.Q., Gao, S., Kareem, A.K., (2016). A numerical study on the effects of exhaust locations on energy consumption and thermal environment in an office room served by displacement ventilation. Energy Conversion and Management. 117: 74-85. doi: 10.1016/j.enconman.2016.03.004.

[2] Ozsagıroglu, S., (2020). Bir mahalin termal konfor şartlarinin hesaplamali akişkanlar dinamiği yöntemi ile analizi. Yildiz Teknik Üniversitesi, (2020).

[3] Volkov, A.A., Sedov, A. V., Chelyshkov, P.D., (2014). Modelling the thermal comfort of internal building spaces in social buildings. Procedia Engineering. 91(TFoCE): 362-7. doi: 10.1016/j.proeng.2014.12.075.

[4] Bilgili, M., Şahin, B., Şimşek, E., Özbek, A., Yaşar, A., (2019). Heat Loss and Exergy Flow through Respiration of the Human Body under Different Meteorological Conditions. European Mechanical Science. 3(2): 45-51. doi: 10.26701/ems.531702.

[5] Awad, A.S., Calay, R.K., Badran, O.O., Holdo, A.E., (2008). An experimental study of stratified flow in enclosures. Applied Thermal Engineering. 28(17-18): 2150-8. doi: 10.1016/j.applthermaleng.2007.12.017.

[6] Cheng, Y., Niu, J., Du, Z., Lei, Y., (2015). Investigation on the thermal comfort and energy efficiency of stratified air distribution systems. Energy for Sustainable Development. 28: 1-9. doi: 10.1016/j. esd.2015.05.007.

[7] KEE-CHIANG CHUNG., JEN-YU Kuo., (1999). Location on Thermal Comfort Analysis with Different Air Distribution Strategies. J. THERMAL EN1/ \& BLDG.\& BLDG. 22: 208-29.

[8] He, G., Yang, X., Srebric, J., (2005). Removal of contaminants released from room surfaces by displacement and mixing ventilation: Modeling and validation. Indoor Air. 15(5): 367-80. doi: 10.1111/j.16000668.2005.00383.x.

[9] d'Ambrosio Alfano, F.R., lanniello, E., Palella, B.I., (2013). PMV-PPD and acceptability in naturally ventilated schools. Building and Environment. 67: 129-37. doi: 10.1016/j.buildenv.2013.05.013.

[10] Li, Q., Zhang, T., Lv, W., (2009). European Journal of Medicinal Chemistry Original article A novel spectrophotometric method for the determination of aminophylline with boric acid in pharmaceutical and mixed serum samples. European Journal of Medicinal Chemistry. 44(4): 1452-6. doi: 10.1016/j.ejmech.2008.09.046.
[11] Han. WP., Gu. XL., (2008). Application of binnacles to terminal 3 of Beijing Capital-International Airport and air distribution simulation. J HVAC. 38(115): 9.

[12] Lau, S.S.Y., Zhang, J., Tao, Y., (2019). A comparative study of thermal comfort in learning spaces using three different ventilation strategies on a tropical university campus. Building and Environment. 148: 579-99. doi: 10.1016/j.buildenv.2018.11.032.

[13] Khalil, A., Bassuoni, M.M., Elsamadony, M.O., Raslan, M.A., (2020). Assessment of Thermal Comfort in Operating Rooms Using PMVPPD Model 2.

[14] Marchenko, A., Temeljotov-Salaj, A., Rizzardi, V., Oksavik, O., (2020). The study of facial muscle movements for non-invasive thermal discomfort detection via bio-sensing technology. Part I: Development of the experimental design and description of the collected data. Applied Sciences (Switzerland). 10(20): 1-29. doi: 10.3390/ app10207315.

[15] Shaharon, M.N., Jalaludin, J., (2012). Thermal comfort assessment-a study toward workers' satisfaction in a low energy office building. American Journal of Applied Sciences. 9(7): 1037-45. doi: 10.3844/ ajassp.2012.1037.1045.

[16] Nasıf Kuru, M., Yilmaz, A., Aktaş, A.E., Erdinç, M.T., (2020). Numerical investigation of flow and heat transfer in axially-finned in-line tube banks. Energy Sources, Part A: Recovery, Utilization and Environmental Effects. 1-16. doi: 10.1080/15567036.2020.1826600.

[17] Yildirim, A., (2019). Numerical and experimental investigastion of velocity and temperature distrubution of an air conditioned room. Osmaniye Korkut Ata University, (2019).

[18] Yildirim, A., Ozalp, C., (2019). Jet Lüle ile İklimlendirmesi Yapılan Bir Ofis Modelinde Konfor Seviyesinin (PMV/PPD) Sayısal Olarak Belirlenmesi. Çukurova University Journal of the Faculty of Engineering and Architecture. 34(September): 207-17. 